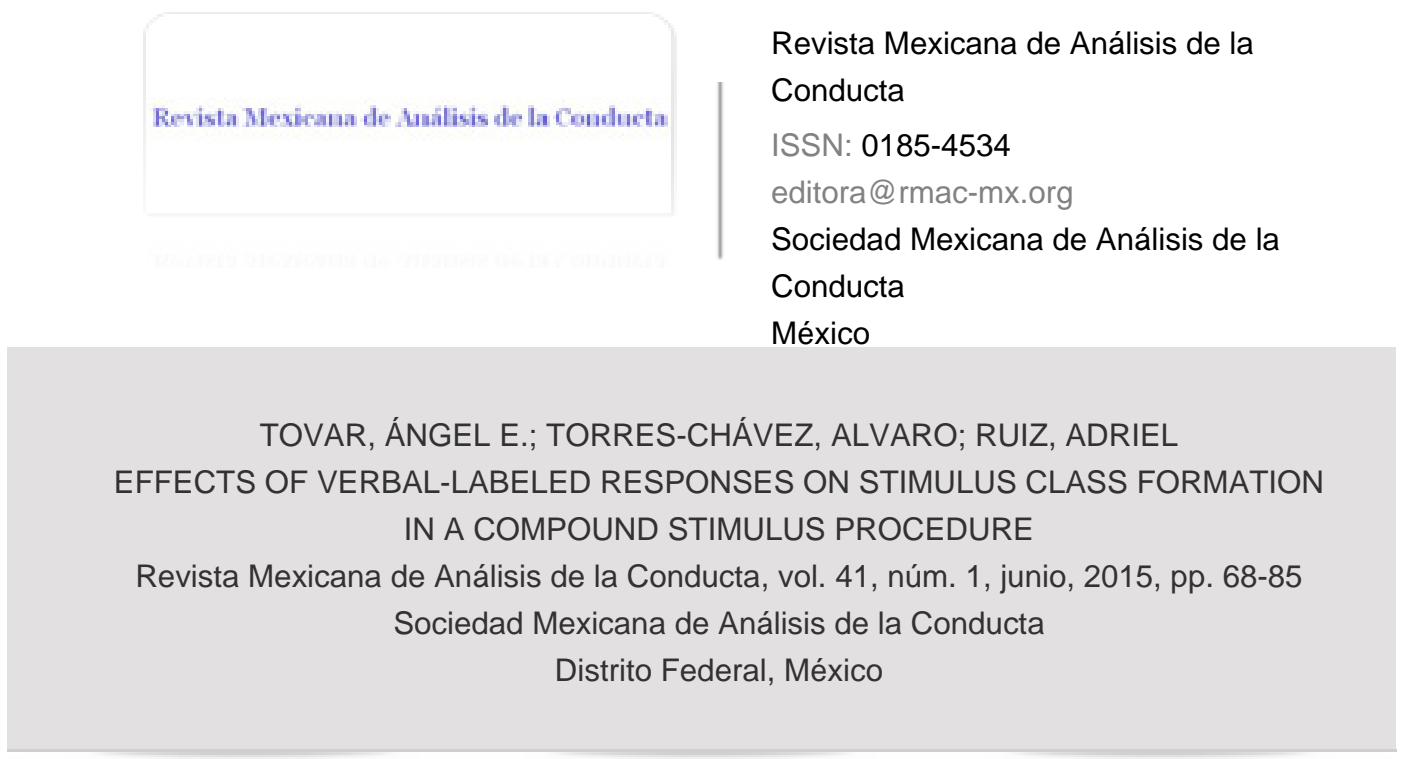

Available in: http://www.redalyc.org/articulo.oa?id=59338802004

- How to cite

- Complete issue

More information about this article

Journal's homepage in redalyc.org

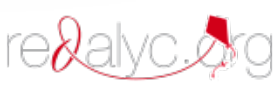

Scientific Information System Network of Scientific Journals from Latin America, the Caribbean, Spain and Portugal Non-profit academic project, developed under the open access initiative 


\title{
EFFECTS OF VERBAL-LABELED RESPONSES ON STIMULUS CLASS FORMATION IN A COMPOUND STIMULUS PROCEDURE
}

\author{
EFECTOS DE RESPUESTAS CON ETIQUETAS VERBALES \\ SOBRE LA FORMACIÓN DE CLASES DE ESTÍMULO EN UN \\ PROCEDIMIENTO DE ESTIIMULO COMPUESTO
}

\author{
ÁNGEL E. TOVAR, ALVARO TORRES-CHÁVEZ, \\ AND ADRIEL RUIZ \\ FACULTAD DE PSICOLOGÍA \\ UNIVERSIDAD NACIONAL AUTÓNOMA DE MÉXICO
}

\begin{abstract}
Evidence suggests that humans form stimulus classes when they learn the baseline relations in a compound stimulus format with two response options. When two 3-member stimulus classes are trained with these procedures, the training contingencies establish the possibility of evoking any of the response options for the within-class transitive compound stimuli; this is described as an ambiguous set of training trajectories. We argue that verbal labels on the response options help human participants surpass the ambiguous training. Here, six adults were assigned to one experimental condition with verbal labels on the response options, other six participants served the second experimental condition with color patches on the response options. Five out of six participants responding with verbal labels responded correctly to symmetry and transitivity tests. Only one participant responding with colors responded correctly to those tests. We discuss a possible role of verbal mediation during equivalence class formation in these procedures.

Keywords: stimulus class formation, categorization, humans, verbal mediation

This study was supported by UNAM-DGAPA (PAPIIT-IN304413). We are grateful for considerable time and extended effort by Kennon A. Lattal in reviewing earlier versions of the manuscript. Correspondence concerning this article should be addressed to Angel E. Tovar, or Alvaro Torres-Chávez, both at Departamento de Psicología Experimental, Universidad Nacional Autónoma de México. México, Distrito Federal, Coyoacán, Código postal 04510. Email: eugeniot@comunidad.unam.mx or alvarot@unam.mx.
\end{abstract}




\section{Resumen}

Los seres humanos pueden formar clases estímulo si aprenden las relaciones de línea base en un formato de estímulos compuestos con dos opciones de respuesta. Cuando se establecen dos clases de 3 miembros con estos procedimientos, las contingencias del entrenamiento establecen la posibilidad de evocar cualquiera de las dos opciones de respuesta ante estímulos compuestos transitivos intra-clase; esto se ha descrito como un conjunto ambiguo de trayectorias de entrenamiento. Aquí argumentamos que las etiquetas verbales en las opciones de respuesta ayudan a los participantes a sobrepasar el entrenamiento ambiguo. Doce adultos participaron en este estudio, fueron asignados a una de dos condiciones experimentales, en la primera condición se les entrenó usando etiquetas verbales en las opciones de respuesta, y en la segunda condición usando parches de colores en las opciones de respuesta. Cinco de los seis participantes con etiquetas verbales respondieron correctamente en las pruebas de simetría y transitividad, mientras que sólo uno de los participantes con parches de colores respondió correctamente en esas pruebas. Discutimos un posible rol de la mediación verbal en la formación de clases en este tipo de procedimientos de estímulos compuestos con dos opciones de respuesta.

Palabras clave: Formación de clases estímulo, categorización, humanos, mediación verbal.

Research on stimulus class formation and stimulus equivalence has focused on analyzing the necessary conditions under which organisms learn that physically disparate stimuli become functionally interchangeably under certain context. It has been proposed that a number of complex human behavioral repertories, such as those involved in concept formation, meaning, syntax, and in general those related to symbolic behavior, can be analyzed with stimulus equivalence methods (e.g., Dickins \& Dickins, 2001; Wilkinson \& Mcllvane, 2001; Zentall, Galizio \& Critchfield, 2002). This is in part because symbolic behavior can be operationalized in terms of emergent stimulus relations and transfer of stimulus control between physically disparate stimuli (stimulus class members). The extent to which equivalence is found across a variety of conditions (e.g., with different stimuli, training formats, participants) strengthens this model.

Stimulus class formation is traditionally studied with conditional discrimination procedures, commonly in the form of conditional discrimination trials (involving a procedure conventionally labeled "matching-to-sample) in which participants learn baseline conditional relations between stimuli, for example, learning to choose Stimulus B1 in the presence of $A 1$, and Stimulus $C 1$ in the presence of B1 establishes the relations $\mathrm{A} 1 \mathrm{~B} 1$ and $\mathrm{B} 1 \mathrm{C} 1$. After such training, new stimulus relations characterized 
by set theory terminology (i.e., reflexive [A1A1], symmetric [B1A1, C1B1], and transitive [A1C1] relations) can be evaluated to reveal the establishment of equivalence relations among stimuli (Sidman \& Tailby, 1982; Sidman, 1994). These new nontrained relations are usually referred as derived or emergent. The stimulus control associated with any stimulus of an equivalence class often is transferred to the other class members without explicit training.

Debert and colleagues studied stimulus class formation when compound stimuli were presented in the presence of which participants were required to make go/nogo responses that produced differential consequences (Debert, Huziwara, Faggiani, Simões De Mathis, \& Mcllvane, 2009; Debert, Matos, \& Mcllvane, 2007). In their procedures participants learned to respond in the presence of any within-class compound stimuli, formed by elements from the same class (e.g., A1B1, B1C1), and to not respond in the presence of any cross-class compound stimuli, formed by elements from different classes (e.g., A1B2, B2C1). After this training, participants responded during tests in like manner to new stimulus configurations dependent on class membership. For example, they responded (go) to A1C1, but didn't respond (no-go) to A1C2 (Debert et al., 2007).

Fields, Doran and Marroquin (2009) also reported stimulus class formation using a trace stimulus pairing format; where the components of a stimulus pair are not presented at the same time, but are presented with a short interval between the offset of the first stimulus and the onset of the second, as in Pavlovian trace conditioning, and with yes/no, or same/diff responses. Participants earned reinforcers by responding on a key labeled with the word yes in the presence of within-class stimulus pairs and responding to a key labeled with the word no in the presence of cross-class stimulus pairs. After training two 3-member classes, Fields et al. found that the training contingencies could account for the evocation of both response options in the presence of the within-class emergent pairs. The selection of yes was reinforced for the training trials $\mathrm{A} 1 \mathrm{~B} 1$ and $\mathrm{B} 1 \mathrm{C} 1$, after this training the selection of yes in the presence of the derived relation $\mathrm{A} 1 \mathrm{C} 1$ was expected. However, when considering the cross-class training, A1 and C1 were also linked by Stimulus B2. Because the selection of no was reinforced in the presence of $\mathrm{A} 1 \mathrm{~B} 2$ and $\mathrm{B} 2 \mathrm{C} 1$, the selection of no in the presence of the derived relation $\mathrm{A} 1 \mathrm{C} 1$ could also be expected. Thus, training two 3-member classes with a stimulus pair format and two response options established an ambiguous set of training trajectories for class formation; however, from their procedures and data Fields et al. could not confirm that the existence of these two training trajectories was interfering with their participant's performance.

Tovar and Torres (2012) trained 6 participants in two 3-member stimulus classes by reinforcing a yes response in the presence of within-class compounds (A1B1, B1C1, 
$\mathrm{A} 2 \mathrm{~B} 2, \mathrm{~B} 2 \mathrm{C} 2$ ) and a no response in the presence of cross-class compounds (A1B2, $\mathrm{B} 1 \mathrm{C} 2, \mathrm{~A} 2 \mathrm{~B} 1, \mathrm{~B} 2 \mathrm{C} 1)$. Four out of six participants performed in accord with stimulus class formation during tests. The same ambiguous training trajectory described by Fields et al. (2009) was present the study by Tovar and Torres (2012), they also analyzed the task with a series of simulations that were run in a computational model. The computational model was implemented as an artificial neural network with a number of processing units with modifiable connection weights between them. They focused on why there was a preference for the yes response (over the no response) for within-class transitive compounds during tests. The computational model simulated stimulus class formation in a similar procedure with compound stimuli and two response options. Two different training protocols were compared, the two protocols presented training and tests trials to evaluate formation of the stimulus classes $\mathrm{A} 1 \mathrm{~B} 1 \mathrm{C} 1$, and $\mathrm{A} 2 \mathrm{~B} 2 \mathrm{C} 2$ in a similar manner to the protocol used with the human participants (establishment of baseline $\mathrm{AB}$ and $\mathrm{BC}$ relations by providing reinforcement after each response, and tests on $\mathrm{AC}$ transitive relations without providing any reinforcement); however, one of the protocols also presented additional training on a third class, called the $X Z Y$ class, by means of providing feedback to every possible stimulus-stimulus relation from this class (e.g., $\mathrm{XY}, \mathrm{YX}$, and $\mathrm{XZ}$ ). This training was presented before the learning of $\mathrm{A} 1 \mathrm{~B} 1 \mathrm{C} 1$, and $\mathrm{A} 2 \mathrm{~B} 2 \mathrm{C} 2$.

The computational model responded with yes to the transitive pairs, thus fully formed the stimulus classes $\mathrm{A} 1 \mathrm{~B} 1 \mathrm{C} 1$, and $\mathrm{A} 2 \mathrm{~B} 2 \mathrm{C} 2$ only when additional training of the $X Y Z$ class was programmed. However, the computational model failed to consistently yield class formation when the additional training of the class XYZ was absent; that is, the preference of the yes response for the transitive pairs was observed only after a differential training history associated with the two response options. In the absence of this differential experience, class formation was not consistently documented in the simulation.

A previous study by Pérez-González (1994) illustrates how differential experience with the response options affects establishing relations between the elements of compound stimuli. Using a conditional discrimination procedure with one sample stimulus and three comparisons, Pérez-González trained four participants in A1B1, A2B2, $\mathrm{A} 3 \mathrm{~B} 3, \mathrm{P} 1 \mathrm{Q} 1, \mathrm{P} 2 \mathrm{Q} 2$, and $\mathrm{P} 3 \mathrm{Q} 3$ relations; for example, training of A1B1 consisted of presenting $\mathrm{A} 1$ as the sample, and $\mathrm{B} 1, \mathrm{~B} 2$, and $\mathrm{B} 3$ as comparisons with the selection of B1 producing reinforcement. In a second step he presented compound stimuli formed by $\mathrm{A}$ and $\mathrm{B}$ elements, and two new stimuli $\mathrm{X} 1$ and $\mathrm{X} 2$ as comparisons; selection of $\mathrm{X} 1$ was reinforced in the presence of within-class compound (e.g., A1B1, A2B2) while selection of $\mathrm{X} 2$ was reinforced in the presence of cross-class compounds (e.g., A1B2, A2B1). Then in a test phase compounds formed with P and Q elements were 
presented and the four participants showed transfer of relational control by responding with $\mathrm{X} 1$ to within-class compounds (e.g., P1Q1) and with X2 to cross-class compounds (e.g., $\mathrm{P} 1 \mathrm{Q} 2)$, selections of $\mathrm{X} 1$ were "somehow equivalent to yes responses and selections of X2 ...somehow equivalent to no responses" (Pérez-González, 1994, p.502). The selection of $X 1$ and $X 2$ depended on the preexisting relations between the elements of the compounds. In a second experiment Pérez-González analyzed whether $\mathrm{X} 1$ and $\mathrm{X} 2$ could be used not only to test, but to establish the relation between two novel (i.e., unrelated) stimuli presented in a stimulus compound format; three of the four participants from the previous experiment were trained with trials of novel EF compounds presented along with $\mathrm{X} 1$ and $\mathrm{X} 2$ as comparisons. Selections of $\mathrm{X} 1$ were reinforced for within-class compounds, and selections of X2 for cross-class compounds. Then MTS trials were presented as tests for the establishment of EF relations. All three participants selected F1 in the presence of E1, F2 in the presence of $\mathrm{E} 2$, and $\mathrm{F} 3$ in the presence of $\mathrm{E} 3$.

Perez-González (1994) demonstrated that the learning history associated with the stimuli used as responses in compound stimuli procedures has an effect on the establishment of relations between the elements of the compound. This is consistent with the results from the computational model by Tovar and Torres (2012) where a pre-experimental history of class formation associated with the response options was essential to observe a consistent pattern of responses during tests. Thus, our supposition is that consistent class formation reported in human experiments in conditions of ambiguous training might depend on the particular stimuli used as response options. Two studies described above that reported class formation (Fields et al., 2009; Tovar \& Torres, 2012) implemented verbally labeled responses in conditions of ambiguous training. It is not possible to know the learning history associated with the verbal labels used on the responses of these studies; however, in a first attempt to evaluate our supposition we asked whether the use of verbal labels on the response options has an effect on class formation when compared with response options without verbal labels on them.

\section{Method}

We analyzed the performance of participants in a compound stimuli format in two different training conditions; participants in the first condition responded with verbal labels on the response options, and participants in the second condition responded with color patches on the response options. We use the labels Equivalent and Non-Equivalent on the response options for participants in the first condition, and purple and brown patches on the response options for participants in the second condition. 


\section{Participants}

Ten female and two male college students aged 20-25 years old, Spanish speakers participated in this study. None had prior experience with equivalence research. They were randomly assigned to one of two experimental conditions. Participants L1 to L6 served the Verbal Labels condition and Participants $\mathrm{H} 1$ to H6 served the Colors condition. Participants $\mathrm{H} 1$ and $\mathrm{H} 5$ were males. They obtained partial course credit in one of their psychology courses for their participation. Informed consent was obtained from all of them.

\section{Apparatus}

The experiment was conducted in a $4 \mathrm{~m} \times 6 \mathrm{~m}$ room or in a $6 \mathrm{~m} \times 8 \mathrm{~m}$ room. Only one session was required for training and tests, and participants attended an individual or a group session depending on their personal schedules. During group sessions there was no communication or visual contact between the participants. Each was seated in a chair facing a personal computer, with headphones, a keyboard and a mouse. The mouse was used to select responses. A software program developed in Visual Basic controlled all stimulus presentations and recorded all responses. The stimuli were six abstract forms, some of them taken from Spencer and Chase (1996), arbitrarily assigned to Class 1 or Class 2 by the experimenters; stimuli were designated as A1, B1, C1, A2, B2, and C2, as showed in Figure 1.

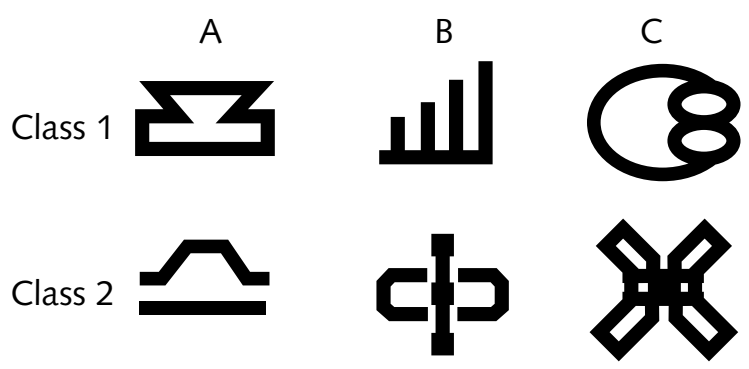

Figure 1. The six abstract figures used as the elements of the stimulus classes.

\section{Procedure}

Two 3-member stimulus classes were trained in a compound stimuli format with two response options. On each trial a compound stimulus appeared at the center of the screen, and two response options appeared on the bottom (see Figure 2). During 
training a counter on the upper left corner of the screen showed the total number of points earned by the participant; this counter was not visible during tests.

Participants were randomly assigned to one of the two experimental conditions; for those serving the Verbal Labels condition a label with the word Equivalentes (Equivalent in Spanish) always appeared on the left response option, and a label with the word No Equivalentes (Non-Equivalent in Spanish) always appeared on the right response option. Participants in the Colors condition always saw a purple patch on a rectangular left response option and a brown patch on a rectangular right response option. Figure 2 shows an example of the elements displayed on the screen for each experimental condition when the relation A1B1 was established.
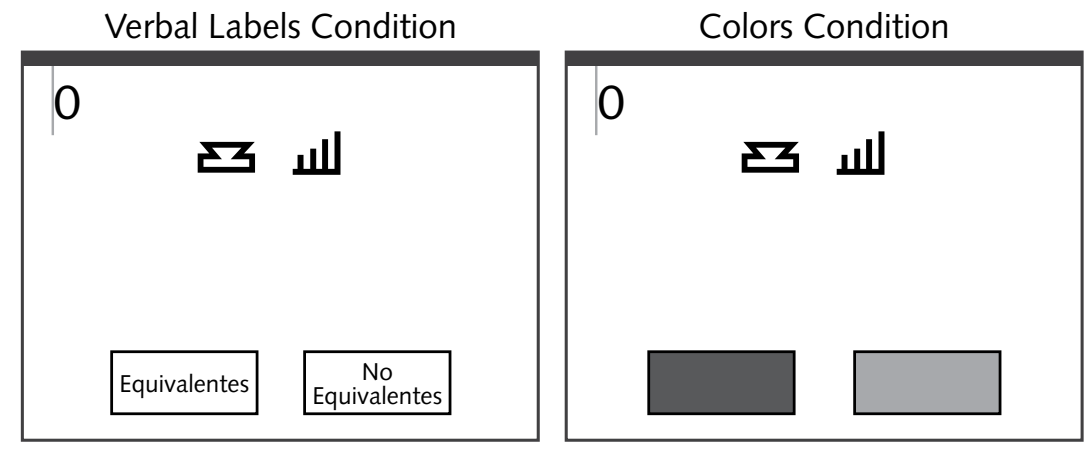

Figure 2. The elements displayed during the training of A1B1 in the Verbal Labels condition (left) and in the Colors condition (right).

Because the only difference between the experimental conditions was the use of labels vs. colors on the response options, to simplify the description of the procedure we hereafter use the expressions "Equivalent/purple" and "Non-Equivalent/brown" without specifying at each moment that only one of the alternatives was used for each response option depending on the experimental condition.

The procedure was divided in three phases; Phase 1 consisted of training the baseline relations between the elements of the compound stimuli. During Phases 2 and 3 , new combinations of compound stimuli represented tests for symmetry and transitivity relations between the elements of the compounds.

Phase 1: Training of Baseline Relations. During this phase participants responded to an Equivalent/purple or a Non-Equivalent/brown option in the presence of each stimulus compound. Responses to the Equivalent/purple option were reinforced in the presence of the within-class compounds $\mathrm{A} 1 \mathrm{~B} 1, \mathrm{~B} 1 \mathrm{C} 1, \mathrm{~A} 2 \mathrm{~B} 2$, and $\mathrm{B} 2 \mathrm{C} 2$; responses to the Non-Equivalent/brown option were reinforced in the presence of the cross- 
class compounds A1B2, B1C2, A2B1, and B2C1. Reinforcement consisted of adding 5 points to the counter, indicated by a 2 -s green-black flickering and an ascending melody on the headphones. Wrong responses were followed by subtracting 5 points from the counter, indicated by a red-black flickering and a descending melody on the headphones. The points on the counter were informative about the participants' performance; however they were not exchangeable for any other items. Trials were separated by 1 -s intertrial intervals.

The nomenclature of the compounds describes the spatial location of each element; for example, each presentation of A1B1 consisted of showing A1 on the left side of the compound and B1 on the right side of the compound, the elements of each compound appeared horizontally separated by a blank space of $2.5 \mathrm{~cm}$ (see Figure 2).

At the beginning of Phase 1, participants read the following instructions (translated from Spanish).

Thank you for your participation.

The following study is not an intelligence test. At the end of the study you will receive a complete explanation.

Your goal is to obtain as many points as possible; these points will be shown on a counter placed in the upper left corner of the screen. The more correct responses you obtain, the faster the task ends.

At the center of the screen two figures will be displayed. At the bottom of the screen you will see two response options. Your task is to select the correct response depending on what figures you see at the center of the screen. You will be able to learn what the correct response is by checking the points on the counter.

Please repeat these instructions to the experimenter and when he approves touch the "Go on" box.

Table 1 shows the sequence of stages and learning criteria used during Phase 1. A total of 8 stimulus pairs were trained during the first 4 stages. During the first stage participants learned to respond with Equivalent/purple to A1B1 and with Non-Equivalent/brown to A1B2, a block of 24 trials was presented with each compound appearing 12 times, once they reached at least 21 correct responses they continued with Stage 2, where A2B2 was associated with Equivalent/purple and A2B1 was associated with Non-Equivalent/brown. Stages 3 and 4 trained B1C1 associated with Equivalent/purple, B1C2 associated with Non-Equivalent/brown; and B2C2 associated with Equivalent/purple, and B2C1 associated with Non-Equivalent/brown, respectively. The trained compounds during each stage were presented in random order; there were no more than three consecutive trials of the same type, and at least 21 correct responses were required as criterion during these 4 stages, otherwise the training block of the failed stage was repeated until mastery criterion was met. 
Table 1.

Sequence of training stages

\begin{tabular}{|c|c|c|c|c|c|}
\hline Stage & $\begin{array}{l}\text { Trained } \\
\text { relations }\end{array}$ & $\begin{array}{c}\text { Correct Response } \\
\text { Labels/Colors }\end{array}$ & $\begin{array}{l}\text { Reinforcement } \\
\text { percentage }\end{array}$ & $\begin{array}{l}\text { Number of } \\
\text { trials }\end{array}$ & Criterion \\
\hline \multirow{2}{*}{1} & A1B1 & Equivalent/Purple & 100 & 12 & \multirow{2}{*}{$21 / 24$} \\
\hline & A1B2 & Non-Equivalent/Brown & 100 & 12 & \\
\hline \multirow{2}{*}{2} & A2B2 & Equivalent/Purple & 100 & 12 & \multirow{2}{*}{$21 / 24$} \\
\hline & A2B1 & Non-Equivalent/Brown & 100 & 12 & \\
\hline \multirow{2}{*}{3} & B1C1 & Equivalent/Purple & 100 & 12 & \multirow{2}{*}{$21 / 24$} \\
\hline & $\mathrm{B} 1 \mathrm{C} 2$ & Non-Equivalent/Brown & 100 & 12 & \\
\hline \multirow{2}{*}{4} & $\mathrm{~B} 2 \mathrm{C} 2$ & Equivalent/Purple & 100 & 12 & \multirow{2}{*}{$21 / 24$} \\
\hline & $\mathrm{B} 2 \mathrm{C} 1$ & Non-Equivalent/Brown & 100 & 12 & \\
\hline \multirow{8}{*}{$\begin{array}{l}5 \\
\text { MIX }\end{array}$} & A1B1 & Equivalent/Purple & 100 & 3 & \multirow{8}{*}{$22 / 24$} \\
\hline & B1C1 & Equivalent/Purple & 100 & 3 & \\
\hline & A2B2 & Equivalent/Purple & 100 & 3 & \\
\hline & $\mathrm{B} 2 \mathrm{C} 2$ & Equivalent/Purple & 100 & 3 & \\
\hline & A1B2 & Non-Equivalent/Brown & 100 & 3 & \\
\hline & $\mathrm{B} 1 \mathrm{C} 2$ & Non-Equivalent/Brown & 100 & 3 & \\
\hline & A2B1 & Non-Equivalent/Brown & 100 & 3 & \\
\hline & $\mathrm{B} 2 \mathrm{C} 1$ & Non-Equivalent/Brown & 100 & 3 & \\
\hline \multirow{8}{*}{$\begin{array}{l}6 \\
\text { MIX } \\
\text { no } \\
\text { reinf. }\end{array}$} & A1B1 & Equivalent/Purple & 0 & 3 & \multirow{8}{*}{$22 / 24$} \\
\hline & B1C1 & Equivalent/Purple & 0 & 3 & \\
\hline & A2B2 & Equivalent/Purple & 0 & 3 & \\
\hline & $\mathrm{B} 2 \mathrm{C} 2$ & Equivalent/Purple & 0 & 3 & \\
\hline & A1B2 & Non-Equivalent/Brown & 0 & 3 & \\
\hline & B1C2 & Non-Equivalent/Brown & 0 & 3 & \\
\hline & A2B1 & Non-Equivalent/Brown & 0 & 3 & \\
\hline & $\mathrm{B} 2 \mathrm{C} 1$ & Non-Equivalent/Brown & 0 & 3 & \\
\hline
\end{tabular}


During Stages 5 and 6, all the compound stimuli were presented in mixed blocks of trials in a random sequence. Twenty-two correct trials were required in Stages 5 and 6, respectively to complete training.

During Stages 1 to 5, all responses generated the programmed consequences. To prepare participants for tests under extinction, during Stage 6 the counter was removed and the participants were told to continue responding according to what they had learned.

Phase 2: Symmetry Tests. During symmetry tests in compound stimuli formats the components of each trained compound are presented in an inverse spatial location; the stimulus presented on the left side of the compound during training is presented on the right side during symmetry tests.

There were eight symmetry relations (B1A1, C1B1, B2A2, C2B2, B2A1, C2B1, $B 1 A 2$, and $C 1 B 2$ ); each one was repeated four times, so a total of 32 trials were presented during this phase without informative feedback. At the beginning participants read the next instructions (translated from Spanish) "This is a new phase and the trials will be different. Please respond in accordance with what you've learned. You will not see the counter in this phase. Please touch on the 'Go on' box to continue."

Phase 3: Transitivity Tests. In this phase participants were tested in new combinations of compound stimuli presented along with baseline trials. A total of 80 trials were presented; each of the baseline relations appeared twice, so a total of 16 trials corresponded to test the maintenance of baseline relations, and each of the next new compound combinations where presented 8 times: A1C1, C1A1, A2C2, C2A2, A1C2, $\mathrm{C} 2 \mathrm{~A} 1, \mathrm{~A} 2 \mathrm{C} 1$, and $\mathrm{C} 1 \mathrm{~A} 2$. No feedback stimuli were presented after each response. At the beginning of this phase participants read the following instructions (translated from Spanish). "This is a new phase; the trials will be different. Please respond in accordance with what you've learned. You will not see the counter in this phase. Please touch on the 'Go on' box to continue."

\section{Results}

\section{Performance during Baseline Training}

All twelve participants completed training as depicted in Figure 3. The mean number of training blocks required by the participants in the Verbal Labels condition was 8.1 , while the mean number of training blocks required by participants in the Colors condition was 13.3. The difference in the number of blocks to complete criteria was pronounced during Stage 5, when all the relations were mixed in the training blocks; for example, four participants in the Verbal Labels condition (L1, L2, L3, and L5) required fewer blocks to master the criterion than five of the participants in the Colors condition $(\mathrm{H} 1, \mathrm{H} 2, \mathrm{H} 3, \mathrm{H} 4$, and $\mathrm{H} 6)$. 
ÁNGEL E. TOVAR et al.

\section{$\frac{1}{\sqrt{0}}$
$\frac{0}{\frac{0}{0}}$
$\frac{\frac{1}{\pi}}{0}$
$\frac{0}{0}$}

L1

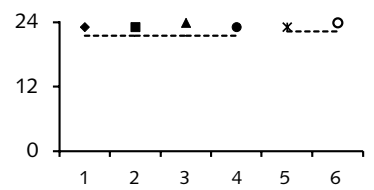

L2

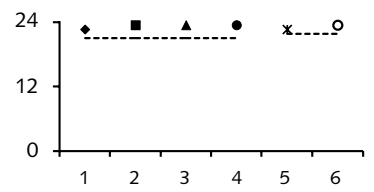

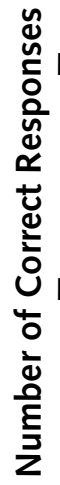

L5

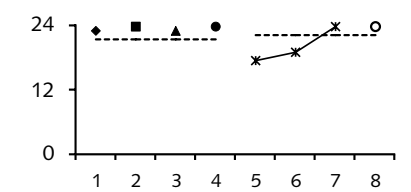

L6

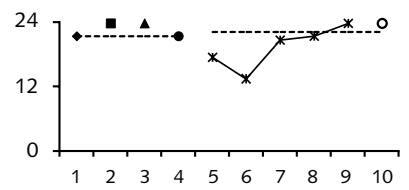

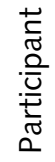

\section{Colors Condition}

H1

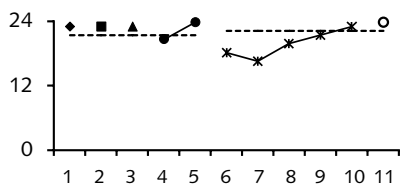

$\mathrm{H} 2$

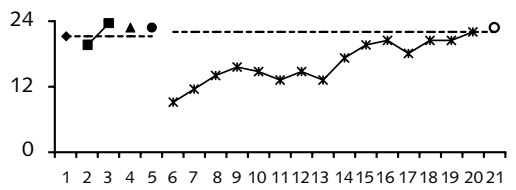

H3

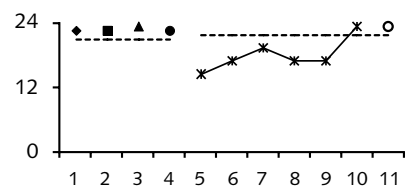

$\mathrm{H} 4$

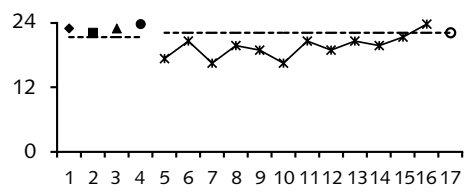

$\mathrm{H} 5$

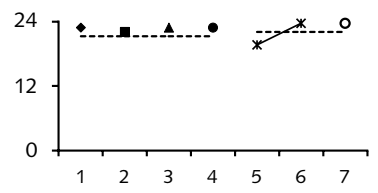

H6

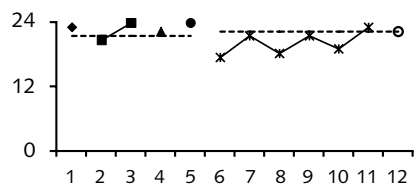

\section{Number of Training Blocks}
- A1B1
$A 1 B 2$
A2B2
A2B1
B1C1
B1C2
$\mathrm{B} 2 \mathrm{C} 2$
* MIX
O MIX No feedback

Figure 3. Individual training data presented as the number of correct responses during each training stage. The dotted lines show the criteria for the 6 training stages. The horizontal axis shows the total number of training blocks required to complete training. 


\section{Performance during Symmetry Tests}

The six participants in the Verbal Labels condition performed with over $90 \%$ of accuracy during the symmetry tests. It is remarkable that Participants L1, L2 and L3 showed an errorless performance during this Phase and they completed the training in the minimum possible number of training blocks. Although participants L4, L5, and L6, required more training blocks to complete the training criteria, they performed with accuracy levels between $93.7 \%$, and $96.8 \%$ in symmetry tests.

Only two participants in the Colors condition, $\mathrm{H} 3$ and $\mathrm{H} 5$, performed with over $90 \%$ of correct responses during this phase, Participant $\mathrm{H} 4$ responded correctly on $71.8 \%$ of the trials, Participant $\mathrm{H} 2$ performed near chance level with only $59 \%$ of correct trials and participants $\mathrm{H} 1$ and $\mathrm{H} 6$ responded correctly to $12.5 \%$ and $6.2 \%$ of the trials, which corresponds to only 4 and 2 correct trials, respectively. This means that participants $\mathrm{H} 1$ and $\mathrm{H} 6$ consistently responded with the inverse option to the symmetry trials, in a post-experimental interview Participant $\mathrm{H} 1$ reported that he could remember the response option associated to each compound stimulus but since he saw the compound in a symmetrical arrangement he decided to change to the other response option in those trials. The percentage of correct trials achieved by each participant during Phase 2 is shown in Table 2.

\section{Performance during Transitivity Tests}

Given that baseline training established an ambiguous trajectory for class formation, participants could group stimuli into classes in different way. Therefore, to assess whether performance during this phase reveal a class formation process we established the following criteria: First, correct choices were required on at least $85 \%$ of the baseline maintenance trials. Second, for the transitive compound stimuli, participants had to respond on at least $85 \%$ of trials using Equivalent/purple for the within-class compounds and Non-Equivalent/brown for the cross-class compounds (i.e., they achieved the within class criteria); or they had to respond to at least $85 \%$ of trials with Equivalent/purple for the cross-class compounds and with Non-Equivalent/brown for the within-class compounds (i.e., they achieved the cross class criteria).

Based on these criteria, five out of six participants in the Verbal Labels condition and one in the Colors condition formed two stimulus classes (see Table 2). Figure 4 shows the frequency of Equivalent/purple and Non-Equivalent/brown responses in the presence of each of the transitive compound stimuli for the 12 participants. The percentage of correct responses to baseline maintenance trials for each participant is indicated in Table 2.

Participants L1, L2, L3, L5 and L6 responded with Equivalent to the within-class compounds and with Non-Equivalent to the cross-class compounds on at least $95 \%$ of the 
trials during this phase. These 5 participants responded correctly to all the baseline maintenance trials. Participant L4 did not show a pattern of class formation; she responded near chance level with only $53.1 \%$ of correct trials, and showed a lower performance on the baseline maintenance trials by responding correctly to only $62.5 \%$ of the trials.

Table 2.

The percentage of correct trials during symmetry tests (Phase 2) and the percentage of correct baseline maintenance trials and transitivity trials (Phase 3) are showed for each participant.

\begin{tabular}{|c|c|c|c|c|}
\hline Participant & $\begin{array}{l}\text { Percentage } \\
\text { of Correct } \\
\text { Trials during } \\
\text { Symmetry } \\
\text { Tests (Phase 2) }\end{array}$ & $\begin{array}{l}\text { Percentage of } \\
\text { Correct Baseline } \\
\text { Maintenance } \\
\text { during Phase } 3\end{array}$ & $\begin{array}{l}\text { Percentage } \\
\text { of Correct } \\
\text { Transitivity Trials } \\
\text { during Phase } \\
3 \text { (within class } \\
\text { criteria) }\end{array}$ & $\begin{array}{c}\text { Class } \\
\text { Formation }\end{array}$ \\
\hline \multicolumn{5}{|c|}{ Verbal Labels Condition } \\
\hline L1 & 100.0 & 100.0 & 100.0 & YES \\
\hline L2 & 100.0 & 100.0 & 100.0 & YES \\
\hline L3 & 100.0 & 100.0 & 100.0 & YES \\
\hline L4 & 93.7 & 62.5 & 53.1 & NO \\
\hline L5 & 96.8 & 100.0 & 95.3 & YES \\
\hline L6 & 96.8 & 100.0 & 90.6 & YES \\
\hline \multicolumn{5}{|c|}{ Colors Condition } \\
\hline $\mathrm{H} 1$ & 12.5 & 62.5 & 45.3 & NO \\
\hline $\mathrm{H} 2$ & 59.3 & 56.3 & 50.0 & NO \\
\hline H3 & 96.8 & 87.5 & 54.6 & NO \\
\hline $\mathrm{H} 4$ & 71.8 & 68.8 & 67.1 & NO \\
\hline $\mathrm{H} 5$ & 100.0 & 100.0 & 100.0 & YES \\
\hline $\mathrm{H} 6$ & 6.2 & 56.3 & 50.0 & NO \\
\hline
\end{tabular}




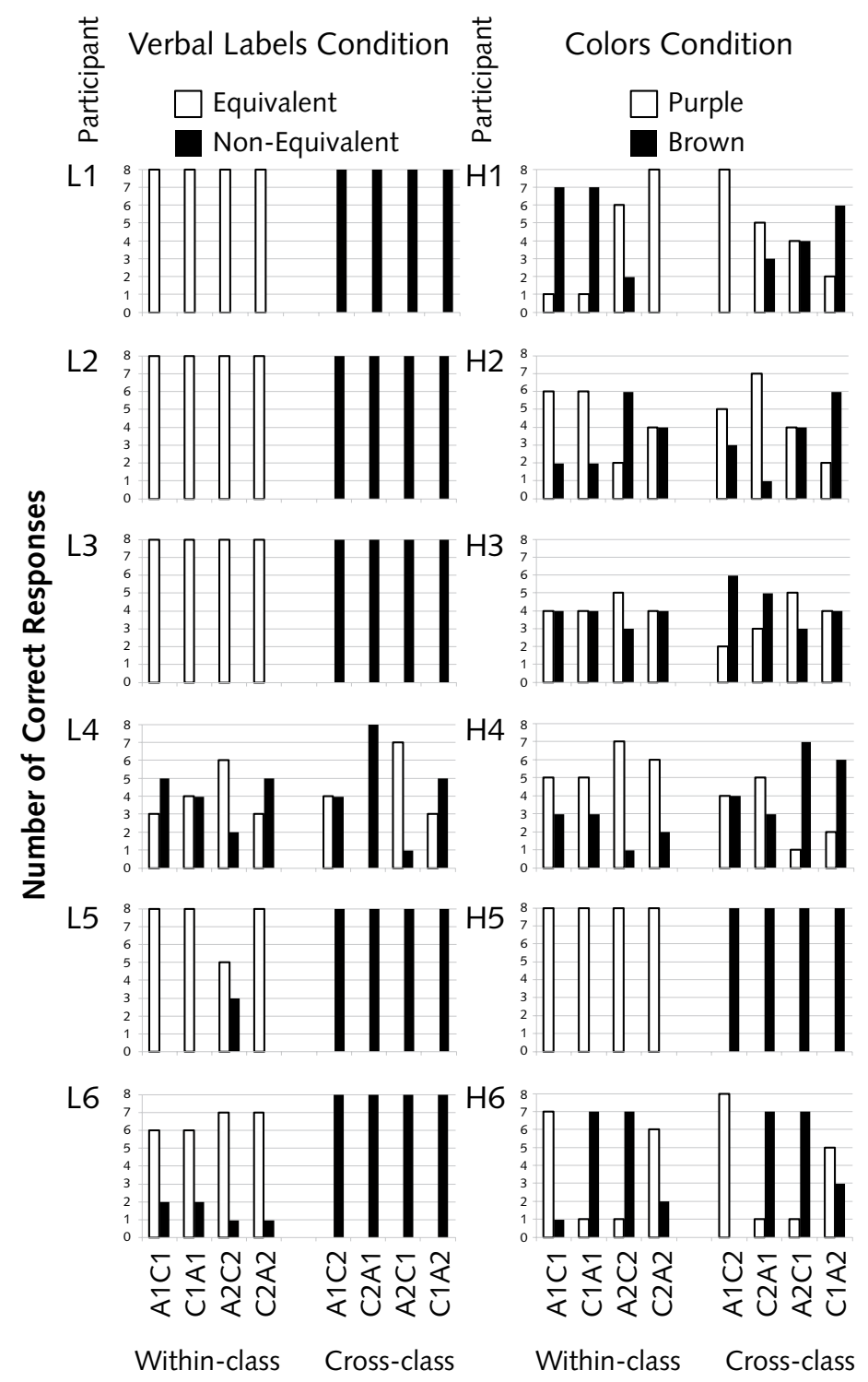

Figure 4. Individual data during transitivity tests. Each bar represents the number of responses emitted in the presence of each compound stimulus shown in the horizontal axis. For participants in the Verbal Labels condition white bars represent the number of responses to the "Equivalent" response option and black bars the number of responses to the "Non-Equivalent" response option. For participants in the Colors condition white bars represent the number of responses to the purple response option and black bars the number of responses to the brown response option. 
Only Participant $\mathrm{H} 5$ in the Colors condition showed a performance indicative of class formation. This participant responded to all the within-class compounds with the purple option and to all the cross-class compounds with the brown option, he also showed an errorless performance on the baseline maintenance trials. Participant $\mathrm{H} 3$ responded correctly to $87.5 \%$ of the baseline maintenance trials, as mentioned previously she also performed with high accuracy levels during symmetry tests $(96.8 \%$ of correct responses), however she did not show a consistent pattern of responding for transitivity trials, as depicted in Figure 4 she sometimes used brown and sometimes purple for the same transitive compounds.

The remaining participants in the Colors condition did not show maintenance of baseline relations, and none showed a consistent pattern of responses for the transitivity trials. As described for Participant H3, they sometimes used the purple response option and sometimes the brown response option for the same compound stimulus. Their data do not correspond to any of our a priori class formation criteria, and it does not show a clear pattern associated with any other class formation process. Participant $\mathrm{H} 6$ seemed to be responding in some trials to only one stimulus of the compound, she always responded with purple when A1 appeared on the left side of the stimulus compound, and with brown when A1 appeared on the right side of the stimulus compound. Besides this pattern we did not find any other consistency in the responses of participants $\mathrm{H} 1, \mathrm{H} 2$, and $\mathrm{H} 4$.

\section{Discussion}

We evaluated the effect of two types of response options, verbally labeled and non-verbally labeled, on the formation of two 3-member stimulus classes in a procedure with compound stimuli and two responses. This procedure generates an ambiguous set of training trajectories for class formation, in which the trained relations established the possibility of evoking any response option during tests for within-class transitivity probes. Due to previous positive results when similar procedures were used (e.g., Fields et al., 2009), our conclusion was that verbal labels on the response options have an effect on the participants performance and promote class formation.

Five out of six participants responding with the verbal labels "Equivalent" and "Non-Equivalent" showed class formation, while only one participant using response options without verbal labels formed classes. This evidence points to a consideration of the influence of verbally labeled responses on class formation when these procedures are used.

The process of stimulus class formation includes the establishment of both trained stimulus relations and derived stimulus relations. It is commonly observed that low accuracy during tests for derived relations is correlated with poor establishment of 
trained relations. This occurred in our study in that all the participants who showed transitivity also performed with high accuracy levels in the baseline maintenance trials, and only one participant $(\mathrm{H} 3)$ who showed high accuracy levels in the baseline maintenance trials did not show transitivity. That is, failures in the transitivity outcome were correlated with a disruption of the baseline relations. Although this observation hinders a direct comparison between the color-labeled and verbally labeled groups with respect to the tests of transitivity and stimulus equivalence, we can conclude that the verbal labels generally resulted in higher performance on the training conditions and that this higher performance resulted in the differences in performance between the two groups on the transitivity and equivalence tests. Furthermore, when analyzing the participants' performance during training we observed that most of the participants in the Verbal Labels condition required fewer training blocks than most of the participants in the Colors condition; and all the participants who formed stimulus classes required fewer training blocks than any of the participants who failed during transitivity tests. From these data we suggest that the use of verbal labels on the response options has an effect on class formation. This was not only observed during transitivity tests, but from the beginning of baseline training, verbal labels promoted a better acquisition and maintenance of trained relations.

The results of this study can be considered in relation to a controversial discussion in the area; the effects of verbal abilities on equivalence class formation (Horne \& Lowe, 1996; Luciano, Gómez-Becerra, Rodríguez-Valverde, 2007; Sidman, 1997). Previous work has shown positive effects of verbal mediation during equivalence class formation. Verbal mediation refers to the enhancing effects of verbal abilities on the establishment of equivalence relations. These effects result from at least two possible situations: providing same names to physically disparate stimuli, or generating a verbal rule that describes the relation between stimuli (Dugdale \& Lowe, 1990). For example, positive effects of verbal abilities on equivalence class formation were described when comparing children with well-established verbal repertories to children with poor verbal repertories. Only those with verbal repertories showed equivalence learning (Devany, Hayes, \& Nelson, 1986). Similar effects were also observed when controlling the "nameability" of the stimuli used to form classes in adult participants (Bentall, Dickins, \& Fox, 1993). The present study shows positive effects on class formation when verbal responses are promoted in conditions of ambiguous stimulus training and tests. To our knowledge, no previous work has analyzed the effects of verbal labels on the compound stimulus training procedures.

Even though all the participants in the Colors condition were adults with typical development and well-established verbal repertories, the use of color patches as response options in combination with the ambiguous training seemed to disrupt or inhibit any verbal response. In a post-experimental interview none of the participants 
from the Colors condition reported the use of names for the stimuli, or any other data to suggest that they used any verbal mediation to solve the task.

Future research might analyze whether similar influences are present in procedures with compound stimuli and go/no-go responses. A number of studies have shown class formation with these procedures (e.g., Debert, et al., 2007; Debert et al., 2009), and while go/no-go responses are free of verbal labels, the verbal instructions associated with the use of these responses could have a similar effect on class formation.

For example, a recent study using pigeons observed symmetry but not transitivity when two 3-member stimulus classes where trained with compound stimuli and go/ no-go responses (Campos, Debert, Da Silva Barrios, \& Mcllvane, 2011), the training could be generating the ambiguous set of trajectories described in this paper. When humans respond in a go/no-go procedure, the verbal instructions could be determining the equivalence outcome, but in the case of pigeons the obvious impossibility of using verbal instructions and the absence of an extra-experimental history associated with the go/no-go responses, may lead to transitivity failures.

The way in which different stimuli are categorized influence concept formation. At the same time, already existing concepts can influence the formation of new categories (e.g., Wisniewski \& Medin, 1994). The present data are an example of how verbally labeled responses attenuate class formation, in contrast with response options without verbal labels. The main result of the present experiment was to show that the particular type of response options used in compound stimulus procedures have a key role on class formation. We found no prior evidence of researchers being aware of this role. Future research might analyze the effects of verbal labels by controlling the learning history with (initially) "nonsense" words used as labels.

\section{References}

Bentall, R. P., Dickins, D. W., \& Fox, S. R. A. (1993). Naming and equivalence: Response latencies for emergent relations. The Quarterly Journal of Experimental Psychology, 46B, 187-214.

Campos, H. C., Debert, P., Da Silva Barros, R., \& Mcllvane, W. J. (2011). Relational discrimination by pigeons in a go/no-go procedure with compound stimuli: a methodological note. Journal of the Experimental Analysis of Behavior, 96 (3), 417-426.

Debert, P., Huziwara, E. M., Faggiani, R. B., Simões De Mathis, M. E., \& Mcllvane, W. J. (2009). Emergent conditional relations in a Go/No-Go procedure: figure-ground and stimulus-position compound relations. Journal of the Experimental Analysis of Behavior, 92 (2), 233-243.

Debert, P., Matos, M. A., \& Mcllvane, W. (2007). Conditional relations with compound abstract stimuli using a go/no-go procedure. Journal of the Experimental Analysis of Behavior, 87 (1), 89-96. 
Devany, J. M., Hayes, S. C., \& Nelson, R. O. (1986). Equivalence class formation in language able and language-disable children. Journal of the Experimental Analysis of Behavior, 46, 243-257.

Dickins, T. E., \& Dickins, D. W. (2001). Symbols, stimulus equivalence and the origins of language. Behavior and Philosophy, 29, 221-244.

Dugdale, N., \& Lowe, C. F. (1990). Naming and stimulus equivalence. In D. E. Blackman \& H. Lejeune. (Eds.) Behavior Analysis in Theory and Practice: Contributions and controversies. (pp. 115-138). Hove, England: Erlbaum.

Fields, L., Doran, E., \& Marroquin, M. (2009). Equivalence class formation in a trace stimulus pairing two-response format: effects of response labels and prior programmed transitivity induction. Journal of the Experimental Analysis of Behavior, 92 (1), 57-84.

Horne, P.J. \& Lowe, C.F. (1996). On the origins of naming and other symbolic behavior. Journal of the Experimental Analysis of Behavior, 65, 185-241.

Luciano, C., Gómez-Becerra, I., \& Rodríguez-Valverde, M. (2007). The Role of Multiple-Exemplar Training and Naming in Establishing Derived Equivalence in an Infant. Journal of the Experimental Analysis of Behavior, 87, 349-365.

Pérez-González, L. A. (1994). Transfer of relational stimulus control in conditional discriminations. Journal of the Experimental Analysis of Behavior, 61, 487-503.

Sidman, M. (1994). Equivalence relations and behavior: A research story. Boston: Authors Cooperative.

Sidman, M. (1997). Equivalence: A Theoretical or a Descriptive Model? Mexican Journal of Behavior Analysis, 23, 125-145.

Sidman, M., \& Tailby, W. (1982). Conditional discrimination vs. matching to sample: an expansion of the testing paradigm. Journal of the Experimental Analysis of Behavior, 37, 5-22.

Spencer, T. J., \& Chase, P. N. (1996). Speed analysis of stimulus equivalence. Journal of the Experimental Analysis of Behavior, 65, 643-659.

Tovar, A., \& Torres, A. (2012). A connectionist model of stimulus class formation with a yes/no procedure and compound stimuli. The Psychological Record, 62, 747-762.

Wilkinson, K. M., \& Mcllvane, W. J. (2001). Methods for studying symbolic behavior and category formation: Contributions of stimulus equivalence research. Developmental Review, 21, 355-374.

Wisniewski, E. J., \& Medin, D. L. (1994). On the interaction of theory and data in concept learning. Cognitive Science, 18, 221-281

Zentall, T. R., Galizio, M., \& Critchfield, T. S. (2002). Categorization, concept learning, and behavior analysis: an introduction. Journal of the Experimental Analysis of Behavior, 78, 237-248. 